\title{
Diagnosis and Management of Piriformis Syndrome: An Osteopathic Approach
}

\author{
Lori A. Boyajian-O'Neill, DO; Rance L. McClain, DO; Michele K. Coleman, DO; and Pamela P. Thomas, PhD
}

Piriformis syndrome is a neuromuscular condition characterized by hip and buttock pain. This syndrome is often overlooked in clinical settings because its presentation may be similar to that of lumbar radiculopathy, primary sacral dysfunction, or innominate dysfunction. The ability to recognize piriformis syndrome requires an understanding of the structure and function of the piriformis muscle and its relationship to the sciatic nerve. The authors review the anatomic and clinical features of this condition, summarizing the osteopathic medical approach to diagnosis and management. A holistic approach to diagnosis requires a thorough neurologic history and physical assessment of the patient based on the pathologic characteristics of piriformis syndrome. The authors note that several nonpharmacologic therapies, including osteopathic manipulative treatment, can be used alone or in conjunction with pharmacotherapeutic options in the management of piriformis syndrome.

J Am Osteopath Assoc. 2008;108:657-664

$P$ iriformis syndrome is a peripheral neuritis of the sciatic nerve caused by an abnormal condition of the piriformis muscle. ${ }^{1}$ It frequently goes unrecognized or is misdiagnosed in clinical settings. Piriformis syndrome can "masquerade" as other common somatic dysfunctions, such as intervertebral discitis, lumbar radiculopathy, primary sacral dysfunction, sacroiliitis, sciatica, and trochanteric bursitis.

More than $16 \%$ of all adult work disability evaluations and examinations are performed to rate the patient's partial or total disability associated with chronic low back pain. ${ }^{2}$ It is estimated that at least $6 \%$ of patients who are diagnosed as having low back pain actually have piriformis syndrome. ${ }^{3-5}$

Delay in diagnosing piriformis syndrome may lead to pathologic conditions of the sciatic nerve, chronic somatic dys-

From the Departments of Family Medicine (Drs Boyajian-O'Neill and McClain) and Anatomy (Dr Thomas) at Kansas City (Mo) University of Medicine and Biosciences College of Osteopathic Medicine, and St John's Episcopal Hospital in Far Rockaway, NY (Dr Coleman).

Address correspondence to Rance L. McClain, DO, Assistant Professor, Department of Family Medicine, Kansas City University of Medicine and Biosciences College of Osteopathic Medicine, 1750 Independence Ave, SEP 358, Kansas City, MO 64106-1453.

E-mail: rmcclain@kcumb.edu

Submitted December 12, 2006; revision received May 2, 2007; accepted July 23, 2007. function, and compensatory changes resulting in pain, paresthesia, hyperesthesia, and muscle weakness. ${ }^{6}$ The challenge for physicians is to recognize symptoms and signs that are unique to piriformis syndrome, enabling appropriate treatment in a timely manner.

The purpose of the present article is to review the pathologic features of piriformis syndrome and the diagnostic criteria and treatments available for patients with this condition. Emphasis is placed on the application of osteopathic principles and practice in diagnosis and treatment.

\section{Methods}

A literature search was conducted using the MEDLINE, OSTMED, Ovid, PubMed, and SPORTDiscus databases. The searches were conducted without limitation on article publication dates. Multiple key terms applicable to piriformis syndrome were used in the searches, including the following: manipulative treatment, obturator internus muscle, osteopathic diagnosis, piriformis, piriformis anatomy, piriformis muscle, piriformis syndrome, sciatica, sciatic nerve, sciatic pain, and somatic dysfunction.

\section{Epidemiologic Considerations}

Piriformis syndrome occurs most frequently during the fourth and fifth decades of life and affects individuals of all occupations and activity levels.7-12 Reported incidence rates for piriformis syndrome among patients with low back pain vary widely, from 5\% to $36 \% .3,4,11$ Piriformis syndrome is more common in women than men, possibly because of biomechanics associated with the wider quadriceps femoris muscle angle (ie, "Q angle") in the os coxae (pelvis) of women. ${ }^{3}$

Difficulties arise in accurately determining the true prevalence of piriformis syndrome because it is frequently confused with other conditions.

\section{Anatomic Characteristics}

The piriformis muscle acts as an external rotator, weak abductor, and weak flexor of the hip, providing postural stability during ambulation and standing. $4,9,13$ The piriformis muscle originates at the anterior surface of the sacrum, usually at the levels of vertebrae S2 through S4, at or near the sacroiliac joint capsule. The muscle attaches to the superior medial aspect of the greater trochanter via a round tendon that, in many individuals, is merged with the tendons of the obturator internus and gemelli muscles (Figure 1).1,13,14 The piriformis 


\section{REVIEW ARTICLE}

muscle is innervated by spinal nerves S1 and S2 - and occasionally also by $\mathrm{L} 5$.

The proper understanding of piriformis syndrome requires knowledge of variations in the relationships between the sciatic nerve and the piriformis muscle (Figure 2). In as much as $96 \%$ of the population, the sciatic nerve exits the greater sciatic foramen deep along the inferior surface of the piriformis muscle. ${ }^{15-17}$ In as much as $22 \%$ of the population, the sciatic nerve pierces the piriformis muscle, splits the piriformis muscle, or both, predisposing these individuals to piriformis syndrome. The sciatic nerve may pass completely through the muscle belly, or the nerve may split-with one branch (usually the fibular portion) piercing the muscle and the other branch (usually the tibial portion) running inferiorly or superiorly along the muscle.7,13-16,18,19 Rarely, the sciatic nerve exits the greater sciatic foramen along the superior surface of the piriformis muscle. $15-17$

Some symptoms of piriformis syndrome occur as a result of local inflammation and congestion caused by the muscular compression of small nerves and vessels-including the pudendal nerve and blood vessels, which exit at the medial inferior border of the piriformis muscle. ${ }^{13}$

\section{Etiologic Considerations}

There are two types of piriformis syndrome-primary and secondary. Primary piriformis syndrome has an anatomic cause, such as a split piriformis muscle, split sciatic nerve, or an anomalous sciatic nerve path. $8,9,20$ Secondary piriformis

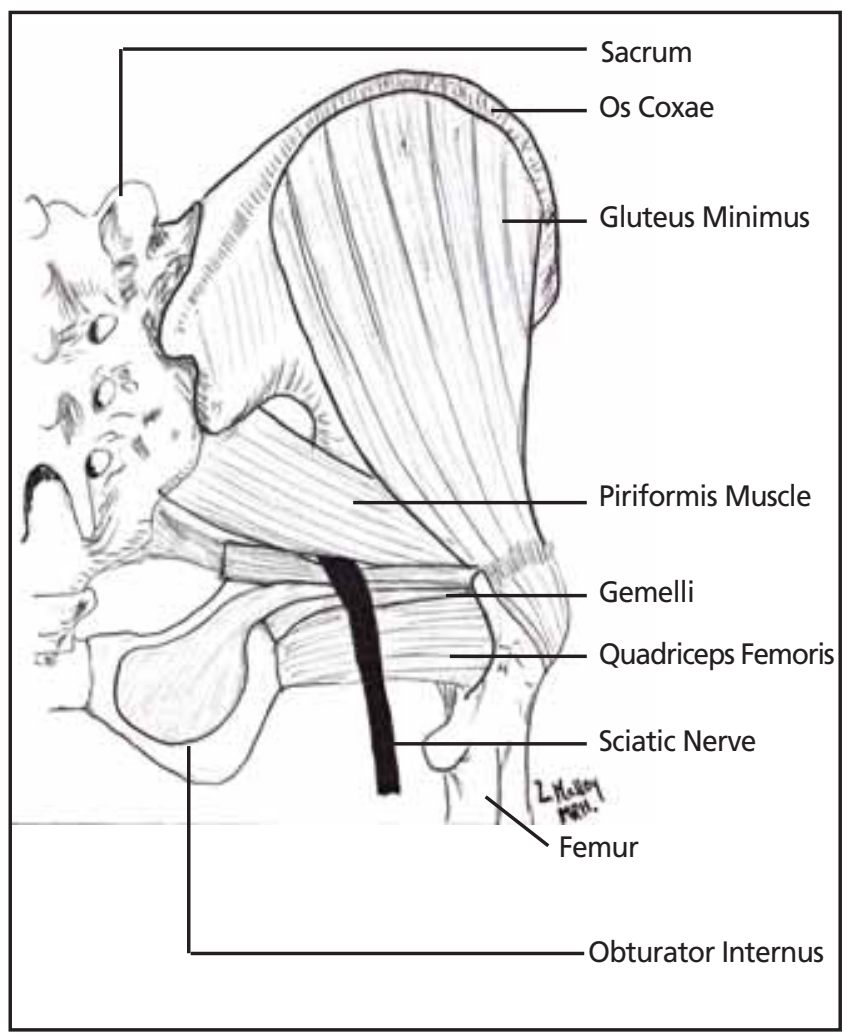

Figure 1. Anatomic features of the hip, including the most common orientation of the sciatic nerve, running inferior to the piriformis muscle.
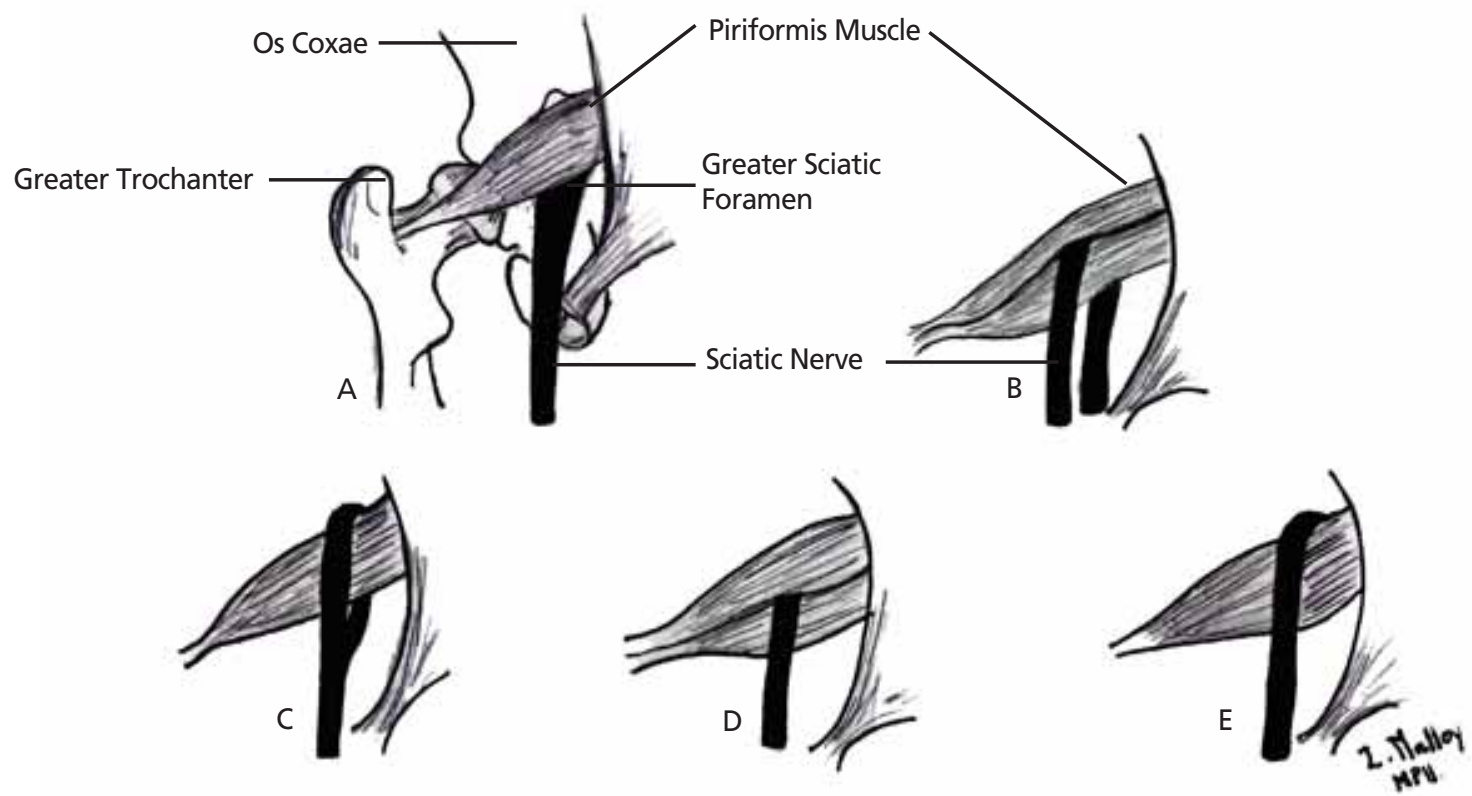

Figure 2. Variations in the relationship of the sciatic nerve to the piriformis muscle: (A) the sciatic nerve exiting the greater sciatic foramen along the inferior surface of the piriformis muscle; the sciatic nerve splitting as it passes through the piriformis muscle with the tibial branch passing (B) inferiorly or (C) superiorly; (D) the entire sciatic nerve passing through the muscle belly; (E) the sciatic nerve exiting the greater sciatic foramen along the superior surface of the piriformis muscle. 
syndrome occurs as a result of a precipitating cause, including macrotrauma, microtrauma, ischemic mass effect, and local ischemia. $1,6,11,21,22$ Among patients with piriformis syndrome, fewer than $15 \%$ of cases have primary causes. 4,11

Piriformis syndrome is most often caused by macrotrauma to the buttocks, leading to inflammation of soft tissue, muscle spasm, or both, with resulting nerve compression. 1,8,9,11,21 Microtrauma may result from overuse of the piriformis muscle, such as in long-distance walking or running or by direct compression. An example of this kind of direct compression is "wallet neuritis" (ie, repetitive trauma from sitting on hard surfaces).

\section{Clinical Diagnosis}

Symptoms of piriformis syndrome are shown below in Figure 3. The most common presenting symptom of patients with piriformis syndrome is increasing pain after sitting for longer than 15 to 20 minutes. Many patients complain of pain over the piriformis muscle (ie, in the buttocks), especially over the muscle's attachments at the sacrum and medial greater trochanter. Symptoms, which may be of sudden or gradual onset, are usually associated with spasm of the piriformis muscle or compression of the sciatic nerve. Patients may complain of difficulty walking and of pain with internal rotation

\section{Symptoms}

$\square$ Pain with sitting, standing, or lying longer than 15 to 20 minutes

$\square$ Pain and/or paresthesia radiating from sacrum through gluteal area and down posterior aspect of thigh, usually stopping above knee

$\square$ Pain improves with ambulation and worsens with no movement

$\square$ Pain when rising from seated or squatting position

$\square$ Change of position does not relieve pain completely

$\checkmark$ Contralateral sacroiliac pain

$\square$ Difficulty walking (eg, antalgic gait, foot drop)

$\square$ Numbness in foot

$\square$ Weakness in ipsilateral lower extremity

$\square$ Headache

$\square$ Neck pain

$\square$ Abdominal, pelvic, and inguinal pain

$\square$ Dyspareunia in women

$\square$ Pain with bowel movements of the ipsilateral leg, such as occurs during cross-legged sitting or ambulation. $1,6,8,8,9,11,21,23$

Spasm of the piriformis muscle and sacral dysfunction (eg, torsion) cause stress on the sacrotuberous ligament. This stress may lead to compression of the pudendal nerves or increased mechanical stress on the innominate bones, potentially causing groin and pelvic pain. $6,9,22$ Compression of the fibular branch of the sciatic nerve often causes pain or paresthesia in the posterior thigh. 1,6,8,9,11,21,23

Through compensatory or facilitative mechanisms, piriformis syndrome may contribute to cervical, thoracic, and lumbosacral pain, as well as to gastrointestinal disorders and headache. 9,22

Clinical signs of piriformis syndrome are shown below in Figure 4. These clinical signs relate, either directly or indirectly, to muscle spasm, resulting nerve compression, or both. Tenderness with palpation over the piriformis muscle, especially over the muscle's attachment at the greater trochanter, is common. Patients may also experience tenderness with palpation in the region of the sacroiliac joint, greater sciatic notch, and piriformis muscle-including pain that may radiate to the knee. $1,6,8,9,11,21,23$

Some patients have a palpable "sausage-shaped" mass in the buttock caused by contraction of the piriformis muscle.6,9,24

\section{Signs}

$\square$ Tenderness in region of sacroiliac joint, greater sciatic notch, and piriformis muscle

$\square$ Tenderness over piriformis muscle

$\square$ Palpable mass in ipsilateral buttock

$\square$ Traction of affected limb provides moderate relief of pain

$\square$ Asymmetrical weakness in affected limb

$\square$ Piriformis sign positive

$\square$ Lasègue sign positive

$\square$ Freiberg sign positive

$\square$ Pace sign (flexion, adduction, and internal rotation test result) positive

$\square$ Beatty test result positive

$\square$ Limited medial rotation of ipsilateral lower extremity

$\square$ Ipsilateral short leg

$\square$ Gluteal atrophy (chronic cases only)

$\square$ Persistent sacral rotation toward contralateral side with compensatory lumbar rotation

Figure 4. Clinical signs of piriformis syndrome.

Figure 3. Clinical symptoms of piriformis syndrome. 
A contracted piriformis muscle also causes ipsilateral external hip rotation. When a patient with piriformis syndrome is relaxed in the supine position, the ipsilateral foot is externally rotated (Figure 5) - a feature referred to as a positive piriformis sign. $6,9,11,21$ Active efforts to bring the foot to midline result in pain. 1,9,24 Many patients with piriformis syndrome also have positive Lasègue, Freiberg, or Pace signs (observed in tests described in the next section of the present article), and these patients may exhibit an antalgic gait. 25

Sacral plexus nerves that innervate the tensor fascia lata, gluteus minimus, gluteus maximus, adductor magnus, quadratus femoris, and obturator externus muscles are also subject to irritation by the piriformis muscle. Ipsilateral muscle weakness may occur if piriformis syndrome is caused by an anatomic anomaly or if it is chronic in duration. 1,4,6,8,9,11,13,17,21,22 Range-of-motion evaluation may reveal decreased internal rotation of the ipsilateral hip in such cases. 1

In most cases of piriformis syndrome, the sacrum is anteriorly rotated toward the ipsilateral side on a contralateral oblique axis, resulting in compensatory rotation of the lower lumbar vertebrae in the opposite direction (Figure 6).6,21 For example, piriformis syndrome on the right side would cause a left-on-left forward sacral torsion with L5 rotated right. Sacral rotation often creates ipsilateral physiologic short leg.6,9,21,26 Facilitation and compensatory somatic dysfunctions may lead to cervical, thoracic, and low back pain.6,9,21,26 TePoorten ${ }^{9}$ reported decreased range of motion at vertebrae T10 and T11, tissue texture changes at $\mathrm{T} 3$ and $\mathrm{T} 4$, pain and decreased range of motion of the contralateral C2, and ipsilateral occiput-atlas lesion in patients with piriformis syndrome.

\section{Diagnostic Tests}

Several clinical tests can be used to aid in the diagnosis of piriformis syndrome. These tests are useful for clarifying clinical situations, though there is no single test specific to piriformis syndrome.

As previously mentioned, tests for Lasègue, Freiberg, and

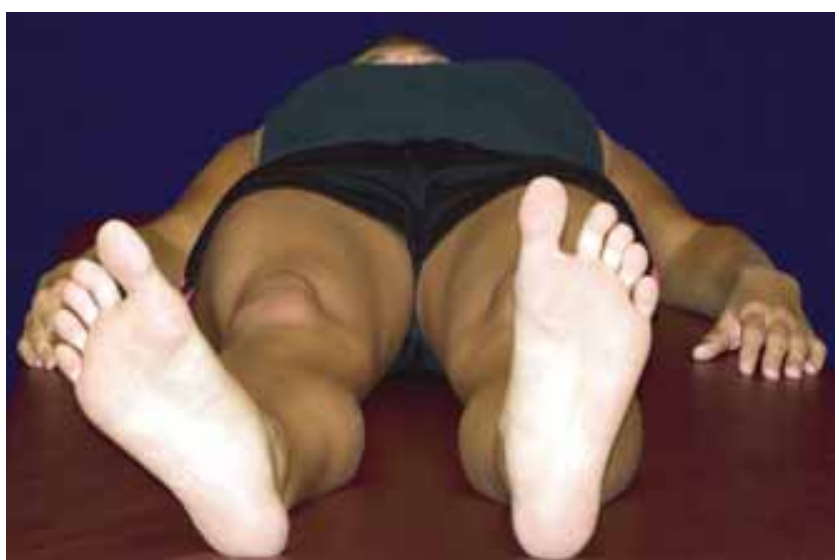

Figure 5. Ipsilateral external rotation of the lower extremity in a patient who is relaxed in the supine position, a positive piriformis sign. (Photograph by Michael D. Roach.)

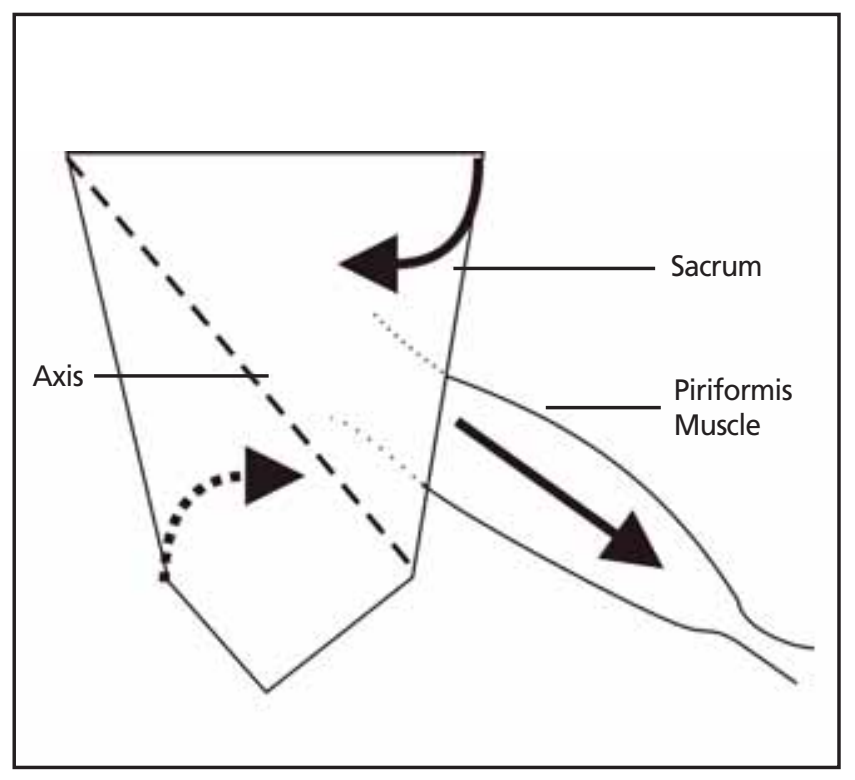

Figure 6. The attachment of the piriformis muscle to the anterior surface of the sacrum, fixing the sacrum's oblique axis on the contralateral side and causing the sacrum to rotate to the ipsilateral side.

Pace signs are used in cases of piriformis syndrome. Lasègue sign is localized pain when pressure is applied over the piriformis muscle and its tendon, especially when the hip is flexed at an angle of 90 degrees and the knee is extended. ${ }^{25}$ Freiberg sign is pain experienced during passive internal rotation of the hip. 25

Pace sign, revealed with the FAIR (flexion, adduction, and internal rotation) test (Figure 7), involves the recreation of sciatic symptoms. ${ }^{25}$ The FAIR test is performed with the patient in a lateral recumbent position, with the affected side up, the hip flexed to an angle of 60 degrees, and the knee flexed to an angle of 60 degrees to 90 degrees. While stabilizing the hip, the examiner internally rotates and adducts the hip by applying downward pressure to the knee. Fishman et al27 found the FAIR test to have sensitivity and specificity of 0.881 and 0.832 , respectively. Alternatively, the FAIR test can be performed with the patient supine or seated, knee and hip flexed, and hip medially rotated, while the patient resists examiner attempts to externally rotate and abduct the hip. The FAIR test result is positive if sciatic symptoms are recreated.3,11,17,25,27,28

The Beatty test is another diagnostic test for piriformis syndrome. ${ }^{12}$ In this test, the patient lies on the unaffected side, lifting and holding the superior knee approximately 4 inches off the examination table. If sciatic symptoms are recreated, the test result is positive.

Neurophysiologic testing can also be used in the diagnosis of piriformis syndrome. Electromyography (EMG) may be beneficial in differentiating piriformis syndrome from intervertebral disc herniation. 1,3,8,29 Interspinal nerve impingement will cause EMG abnormalities of muscles proximal to the pir- 
iformis muscle. In patients with piriformis syndrome, EMG results will be normal for muscles proximal to the piriformis muscle and abnormal for muscles distal to it. Electromyography examinations that incorporate active maneuvers, such as the FAIR test, may have greater specificity and sensitivity than other available tests for the diagnosis of piriformis syndrome. 30

Radiographic studies have limited application to the diagnosis of piriformis syndrome. Although magnetic resonance imaging and computed tomography may reveal enlargement of the piriformis muscle, these imaging technologies are most useful in this setting when ruling out disc and vertebral pathologic conditions. $8,17,31-33$

\section{Differential Diagnosis}

Piriformis syndrome may mimic other conditions. Alternatively, it may be a comorbid condition or considered in a differential diagnosis. A complete neurologic history and physical assessment of the patient is essential for accurate diagnosis. This history and physical assessment should encompass any trauma to the buttocks and the presence of any bowel and bladder changes. 3,9 The physical assessment should also include the following:

$\square$ an osteopathic structural examination with special attention to the lumbar spine, pelvis, and sacrum, as well as any leg length disparities 921,26

$\square$ the diagnostic tests previously mentioned $12,25,27$

$\square$ deep-tendon reflex testing and strength and sensory testing $1,3,8,29$

A combination of the medical history and physical assessment as well as neurologic and radiologic testing can be used to rule out lumbosacral radiculopathies, degenerative disc disease, compression fractures, and spinal stenosis. Radiculopathies are usually accompanied by both proximal and distal muscle weakness and atrophy. By contrast, patients with piriformis syndrome typically exhibit weakness and atrophy only in distal musculature. ${ }^{27,28}$ Sacroiliitis, other sacroiliac joint dysfunction, and somatic dysfunction of the sacrum and innominates should be considered as possible causes or effects of piriformis syndrome and can be determined with a thorough osteopathic structural examination and radiographic testing. $1,4,8,9,17,21,22$

Leg length discrepancy warrants an investigation to distinguish between physiologic or anatomic causes.9,21,26 Diseases of the hip, including arthritis and bursitis, as well as fracture, should be considered in differential diagnoses. Computed tomography, magnetic resonance imaging, and ultrasound technologies can be used to rule out referred pain from gastrointestinal or pelvic causes, such as colon cancer, endometriosis, and interstitial cystitis. 4,6,11,25,34

The obturator internus muscle, which also acts as an external hip rotator, has been suggested as a contributing

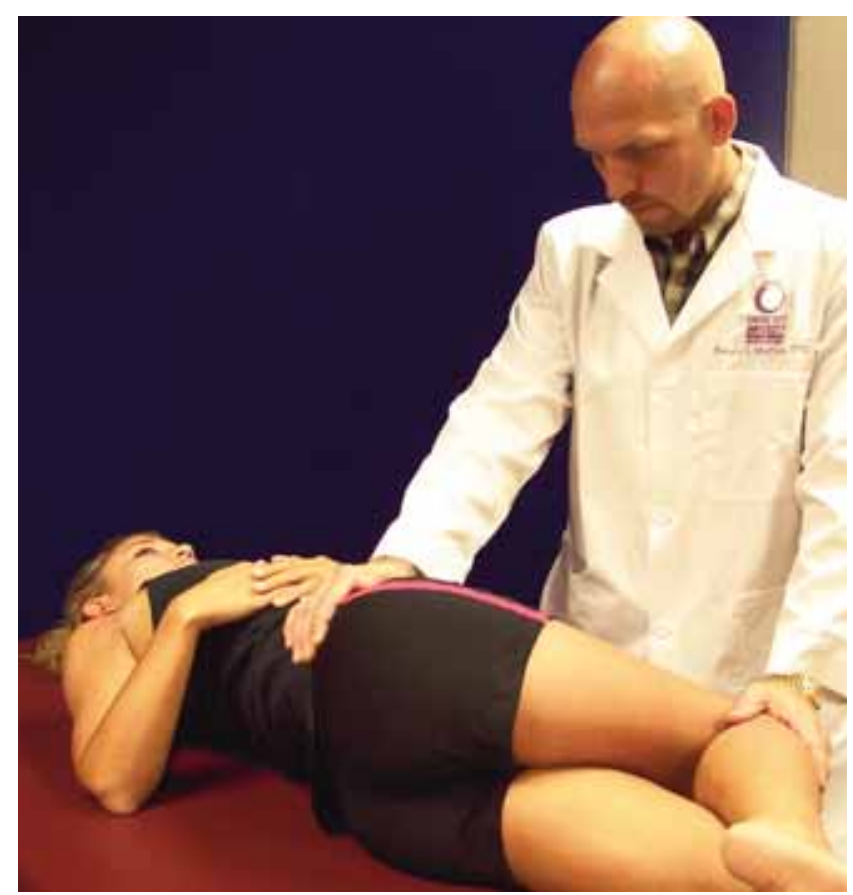

Figure 7. Coinvestigator Rance L. McClain, DO, demonstrates the FAIR (flexion, adduction, and internal rotation) test. The FAIR test is performed with the patient in a lateral recumbent position, with the affected side up, the hip flexed to an angle of 60 degrees, and the knee flexed to an angle of 60 degrees to 90 degrees. While stabilizing the hip, the examiner internally rotates and adducts the hip by applying downward pressure to the knee. (Photograph by Michael D. Roach.)

source of the sciatic neuritis observed in patients with possible piriformis syndrome. In a study 35 of 6 patients who underwent surgery for suspected piriformis syndrome, all were observed intraoperatively to have increased obturator internus muscle tension, hyperemia, and hypertrophy. Furthermore, the obturator internus muscle was observed impinging on the sciatic nerve during an intraoperative Lasègue maneuver. ${ }^{35}$ Anatomically, the obturator internus is deep to both the piriformis muscle and the sciatic nerve, and it parallels the piriformis in its attachments. ${ }^{13}$ Because of this proximity, similar pathway, and similar function, most treatments for patients with piriformis syndrome would affect the internal obturator muscle as well.

\section{Treatment}

Throughout the physical evaluation of patients, clinicians should maintain a high index of suspicion for piriformis syndrome. Early conservative treatment is the most effective treatment, as noted by Fishman et al, ${ }^{27}$ who reported that more than $79 \%$ of patients with piriformis syndrome had symptom reduction with use of nonsteroidal anti-inflammatory drugs (NSAIDs), muscle relaxants, ice, and rest.

Stretching of the piriformis muscle and strengthening of 
the abductor and adductor muscles should also be included in patient treatment plans. ${ }^{34} \mathrm{~A}$ manual medicine approach may combine muscle stretches, Gebauer's spray and stretch technique, and soft tissue, myofascial, muscle energy, and thrust techniques to address all somatic dysfunctions in the patient with piriformis syndrome. $14,6,9$ If the patient does not respond adequately to manual treatment, then acupuncture and trigger point injection with lidocaine hydrochloride, steroids, or botulinum toxin type A (BTX-A) may be considered.4,17,25,36

If all of the pharmacologic and manual medicine treatments fail, the final treatment option is surgical decompression. $4,8,9,16$

\section{Pharmacologic Treatment}

Nonsteroidal anti-inflammatory drugs and acetaminophen have been considered the medications of choice in the management of the many conditions that manifest as low back pain, including piriformis syndrome. ${ }^{37}$ Patients using NSAIDs, compared with those using placebo, reported global reduction of symptoms after 1 week of treatment. 38

Muscle relaxants are another frequently prescribed medication for patients with piriformis syndrome. Patients using muscle relaxants are nearly five times as likely to report symptom improvement by day 14 , compared with patients given placebo. ${ }^{39}$ Common adverse effects of muscle relaxants are dryness of mouth, drowsiness, and dizziness.

Few studies have examined the role of narcotic analgesics in managing acute vs chronic musculoskeletal pain. However, it is clear that some patients with chronic pain do benefit from these medications. ${ }^{40,41}$ Narcotics can be helpful in controlling episodes of severe or debilitating pain, but they should be considered a short-term treatment only. Constipation, gastrointestinal upset, and sedation are common adverse effects of narcotic medications. In addition, the potential for addiction should always be considered when initiating treatment with medications from this drug class.

Local steroid injections can produce an anti-inflammatory effect. Although evidence for the efficacy of steroids in cases of chronic musculoskeletal pain is inconclusive, steroid injections have proven helpful in the treatment of carefully selected patients. 42 Infection is the most common complication of this invasive treatment.

Other potential treatments for patients with piriformis syndrome include prolotherapy (ie, sclerotherapy, ligament reconstructive therapy). This kind of treatment involves injection of an irritating solution at the origin or insertion of ligaments or tendons to strengthen the weakened or damaged connective tissue..$^{43}$ There is little published research regarding the efficacy of this treatment option. Infection is the most common complication of prolotherapy.

\section{Osteopathic Manipulative Treatment}

The goals of osteopathic manipulative treatment (OMT) for patients who have piriformis syndrome are to restore normal range of motion and decrease pain. These goals can be achieved by decreasing piriformis spasm. Indirect osteopathic manipulative techniques have been used to treat patients with piriformis syndrome. The two indirect OMT techniques most commonly reported for the management of piriformis syndrome are counterstrain and facilitated positional release.1,26 Both techniques involve the principle of removing as much tension from the piriformis muscle as possible.

Three tender point locations can be addressed with counterstrain - at the midpole sacrum, piriformis muscle, and posteromedial trochanter. ${ }^{1}$ To position a patient for counterstrain treatment, the patient is generally asked to lie in a prone position with the affected side of the body at the edge of the examination table. In performing the counterstrain technique, the osteopathic physician brings the patient's affected leg over the side of the table, placing it into flexion at the hip and knee, with abduction and external rotation at the hip (Figure 8).

Facilitated positional release can also be achieved from the position shown in Figure 8, with compression through the long axis of the femur from the knee toward the sciatic notch. This additional compressive force can reduce patient treatment time from 90 seconds when performing counterstrain to 3 to 5 seconds when performing facilitated positional release. ${ }^{1}$

Direct OMT techniques can be performed using either active or passive methods. The direct OMT techniques that are the most useful in treating patients with piriformis syndrome include muscle energy, articulatory, Still, and high velocity/low amplitude. ${ }^{1}$ The muscle energy technique can be applied in the management of piriformis spasm, as well as for associated dysfunctions of the sacrum and pelvis. No absolute contraindications are defined for the muscle energy technique. The patient must understand the required amount of muscular force and the correct direction of this force for the technique to be effective. ${ }^{1}$

Articulatory OMT techniques are applied by advancing and retreating from a restrictive barrier in a repetitive manner to advance that barrier and increase the range of motion. The presence of osteoarthritis can limit the applicability of this technique secondary to articulatory pain. ${ }^{44}$ The Still technique, a specialized form of articulatory treatment, is begun by placing a joint in a relaxed position away from restrictive barriers. Then, with an arching motion, compression is applied to the level of dysfunction and moved toward the restrictive barrier while the patient is passive and relaxed. No absolute contraindications are defined for the Still technique. 45

High velocity/low amplitude technique is most often used in cases of piriformis syndrome to correct associated sacral and pelvic somatic dysfunctions. Extreme caution should be exercised when using this manual technique with individuals who have osteoporosis. ${ }^{1}$

\section{Physical Therapy}

Patients with piriformis syndrome may be treated with physical therapy involving a variety of motion exercises and 


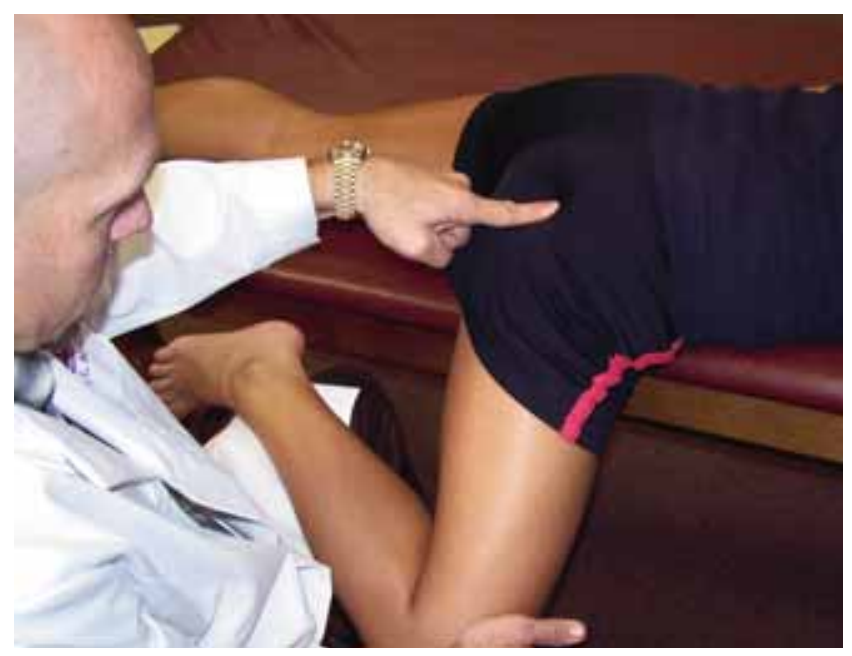

Figure 8. Coinvestigator Rance L. McClain, DO, demonstrates application of the counterstrain technique of osteopathic manipulative treatment as used to treat the piriformis counterstrain point. (Photograph by Michael D. Roach.)

stretching techniques. It is important for the physician to clearly demonstrate the stretches that the patient is expected to perform. It is also advisable to have the patient perform these exercises for the first time in the office, where the physician can observe and modify the patient's techniques, as needed. If the patient demonstrates excessive difficulty in understanding or performing the exercises, the physician can refer the patient to a licensed physical therapist for assistance.

If a patient is able to perform the required exercises at home, he or she should be advised to do so in multiple short sessions each day, with each session lasting only a few minutes. Physical therapy in a professional setting is commonly performed in two or three sessions per week for the duration of the treatment regimen, with each session lasting somewhat longer than it would take the patient to perform the same actions independently during a home exercise session. 46

The ultimate goal of physical therapy is symptom elimination through a systematic program designed to increase the range of motion of the surrounding muscle groups and joints, as well as to increase the supporting strength of these muscle groups. In particular, the strengthening of the adductor muscles of the hip has been shown to be beneficial for patients with piriformis syndrome. 17

Several studies 5,22,46,47 have reported that additional benefit can be derived from physical therapy modalities, such as heat therapy, cold therapy, BTX-A injection, and ultrasound. Heat or cold therapy is usually most effectively applied before the physical therapy or home therapy sessions because it may lessen the discomfort associated with direct treatment applied to an irritated or tense piriformis muscle.22,46,47 Injections of BTX-A, when used as an adjunct to physical therapy, have been shown to produce more pain relief than lidocaine with steroids or placebo. ${ }^{48}$ Iontophoresis, the use of electrical current to transport solubilized medication across the skin, and sonophoresis, the use of ultrasonic energy to drive the cutaneous transport of medication molecules, have both been advocated as adjuncts to physical therapy though neither has been studied extensively in the treatment of patients with piriformis syndrome. 48

\section{Surgery and Prevention}

As a last resort, surgery has been occasionally used in cases that have failed to resolve with the use of other treatment measures. The goal of surgery in these cases is to reduce any tension under which the piriformis muscle may be placed, as well as to explore the sciatic notch to ensure that there are no fibrous bands or constrictions compressing the sciatic nerve.8,11

Prevention of repetitive trauma (ie, microtrauma) may prove effective in decreasing a patient's risk of piriformis syndrome. Correcting biomechanical deficiencies and functional adaptations to those deficiencies can reduce the incidence of piriformis syndrome.5,47

\section{Conclusion}

There are many gaps in knowledge regarding piriformis syndrome. An increase in the breadth and depth of our understanding of this condition is necessary for optimal patient care. Additional research is needed for patients with piriformis syndrome, primarily concerning epidemiologic factors, risk factors, and optimal treatment. The length of time from symptom onset to initial presentation is not known and needs to be studied further. The proportion of patients presenting with low back pain who demonstrate symptoms and signs consistent with piriformis syndrome is also unknown and merits further consideration.

Piriformis syndrome is a complex condition that is often not considered in the differential diagnosis of chronic hip and low back pain. To aid diagnosis, several tests have been developed to recreate the pain by actively contracting or passively stretching the piriformis muscle and compressing the sciatic nerve. Radiographic studies and neuroelectric tests are primarily used to narrow the differential diagnosis toward piriformis syndrome by ruling out other pathologic conditions.

A holistic approach to diagnosis involves a thorough neurologic history and physical assessment of the patient, inclusive of the osteopathic structural examination, based on the pathologic characteristics of piriformis syndrome. Osteopathic manipulative treatment can be used as one of several possible nonpharmacologic therapies for these patients. Nonpharmacologic therapies can be used alone or in conjunction with pharmacologic treatments in the management of piriformis syndrome in an attempt to avoid surgical intervention.

\section{Acknowledgments}

We thank Angela K. Imes; Nancy Stroud; Mary Clark; Lindsey E. Malloy, DO; Tyler Feikema; and Kevin D. Treffer, DO, for their assistance with this article in manuscript form.

(continued) 


\section{References}

1. DiGiovanna EL, Schiowitz S, Dowling DJ, eds. An Osteopathic Approach to Diagnosis and Treatment. 3rd ed. Philadelphia, Pa: Lippincott Williams \& Wilkins; 2005.

2. Centers for Disease Control and Prevention. Prevalence of disabilities and associated health conditions among adults_United States, 1999 [published correction appears in MMWR Morb Mortal Wkly Rep. 2001;50:149]. MMWR Morb Mortal Wkly Rep. 2001;50:120-125.

3. Pace JB, Nagle D. Piriformis syndrome. West J Med. 1976;124:435-439.

4. Papadopoulos EC, Khan SN. Piriformis syndrome and low back pain: a new classification and review of the literature. Orthop Clin North Am. 2004;35:6571.

5. Hallin RP. Sciatic pain and the piriformis muscle. Postgrad Med. 1983;74:6972.

6. Chaitow L. Soft Tissue Manipulation: A Practitioner's Guide to the Diagnosis and Treatment of Soft-Tissue Dysfunction and Reflex Activity. 3rd ed. Rochester, Vt: Healing Arts Press; 1988.

7. Beaton LE, Anson BJ. The sciatic nerve and the piriformis muscle: their interrelation a possible cause of coccygodynia. J Bone Joint Surg Am. 1938;20:686-688. Available at: http://www.ejbjs.org/cgi/reprint/20/3/686. Accessed September 9, 2008.

8. Benson ER, Schutzer SF. Posttraumatic piriformis syndrome: diagnosis and results of operative treatment. J Bone Joint Surg Am. 1999;81:941-949.

9. TePoorten BA. The piriformis muscle. J Am Osteopath Assoc. 1969;69:150160.

10. Brown JA, Braun MA, Namey TC. Pyriformis syndrome in a 10 -year-old boy as a complication of operation with the patient in a sitting position. Neurosurgery. 1988;23:117-119.

11. Foster MR. Piriformis syndrome. Orthopedics. 2002;25:821-825.

12. Beatty RA. The piriformis muscle syndrome: a simple diagnostic maneuver. Neurosurgery. 1994;34:512-514.

13. Williams PL, Warwick R. Gray's Anatomy. 36th ed. Philadelphia, Pa: WB Saunders Co; 1980.

14. Hollinshead HW. Buttock, hip joint and thigh. In: Anatomy for Surgeons: The Back and Limbs. Vol 3. 2nd ed. New York, NY: Hoeber Medical Division, Harper and Row; 1969:663-666.

15. Beason LE, Anson B.J. The relation of the sciatic nerve and its subdivisions to the piriformis muscle. Anat Record. 1937;70:1-5.

16. Pecina M. Contribution to the etiological explanation of the piriformis syndrome. Acta Anat (Basel). 1979;105:181-187.

17. Benzon HT, Katz JA, Benzon HA, lqbal MS. Piriformis syndrome: anatomic considerations, a new injection technique, and a review of the literature. Anesthesiology. 2003;98:1442-1448.

18. Bergman RA, Afifi AK, Miyauchi R. Illustrated Encyclopedia of Human Anatomic Variation. 1995-2008. Anatomy Atlases Web site. Available at: http://www.anatomyatlases.org/AnatomicVariants/AnatomyHP.shtml. Accessed September 9, 2008.

19. Freiberg $A H$, Vinke TH. Sciatica and the sacro-iliac joint. J Bone Joint Surg Am. 1934;16:126-136. Available at: http://www.ejbjs.org/cgi/reprint/16/1/126. Accessed September 9, 2008.

20. Beauchesne RP, Schutzer SF. Myositis ossificans of the piriformis muscle: an unusual cause of piriformis syndrome: a case report. J Bone Joint Surg Am. 1997;79:906-910.

21. Retzlaff EW, Berry AH, Haight AS, Parente PA, Lichty HA, Turner DM, et al. The piriformis muscle syndrome. J Am Osteopath Assoc. 1974;73:799-807.

22. Steiner C, Staubs C, Ganon M, Buhlinger C. Piriformis syndrome: pathogenesis, diagnosis, and treatment. J Am Osteopath Assoc. 1987;87:318-323.

23. Hughes SS, Goldstein MN, Hicks DG, Pellegrini VD. Extrapelvic compression of the sciatic nerve. An unusual cause of pain about the hip: report of five cases. J Bone Joint Surg Am. 1992;74:1553-1559. Available at: http://www.ejbjs.org/cgi /reprint/74/10/1553. Accessed September 9, 2008.
24. Robinson DR. Pyriformis syndrome in relation to sciatic pain. Am J Surg 1947;73:355-358.

25. Magee DJ. Orthopedic Physical Assessment. 3rd ed. Philadelphia, Pa: WB Saunders Co; 1997.

26. Grant JH. Leg length inequality in piriformis syndrome. J Am Osteopath Assoc. 1987;87:456.

27. Fishman LM, Dombi GW, Michaelsen C, Ringel S, Rozbruch J, Rosner B, et al. Piriformis syndrome: diagnosis, treatment, and outcome-a 10-year study [review]. Arch Phys Med Rehabil. 2002;83:295-301.

28. Fishman LM, Zybert PA. Electrophysiologic evidence of piriformis syndrome. Arch Phys Med Rehabil. 1992;73:359-364.

29. Solheim LF, Siewers $P$, Paus B. The piriformis muscle syndrome. Sciatic nerve entrapment treated with section of the piriformis muscle. Acta Orthop Scand. 1981;52:73-75.

30. Fishman LM, Schaefer MP. The piriformis syndrome is underdiagnosed. Muscle Nerve. 2003;28:646-649.

31. McCrory P, Bell S. Nerve entrapment syndromes as a cause of pain in the hip, groin and buttock [review]. Sports Med. 1999;27:261-274.

32. Hochman MG, Zilberfarb JL. Nerves in a pinch: imaging of nerve compression syndromes. Radiol Clin North Am. 2004;42:221-245.

33. Read MT. The "piriformis syndrome"-myth or reality? Br J Sports Med. 2002;36:76.

34. Prather H. Sacroiliac joint pain: practical management. Clin J Sport Med. 2003;13:252-255

35. Meknas K, Christensen A, Johansen O. The internal obturator muscle may cause sciatic pain. Pain. 2003;104:375-380.

36. De Andres J, Cerda-Olmedo G, Valia JC, Monsalve V, Lopez-Alarcon, Minguez A. Use of botulinum toxin in the treatment of chronic myofascial pain. Clin J Pain. 2003;19:269-275.

37. Harwood MI, Smith BJ. Low back pain: a primary care approach. Clin Fam Pract. 2005;7:56-59.

38. van Tulder MW, Scholten RJ, Koes BW, Deyo RA. Nonsteroidal anti-inflammatory drugs for low back pain: a systematic review within the framework of the Cochrane Collaboration Back Review Group. Spine. 2000;25:25012513.

39. Browning R, Jackson JL, O’Malley PG. Cyclobenzaprine and back pain: a meta-analysis. Arch Intern Med. 2001;161:1613-1620. Available at: http://arch inte.ama-assn.org/cgi/content/full/161/13/1613. Accessed September 9, 2008.

40. Schnitzer RJ, Gray WL, Paster RZ, Kamin M. Efficacy of tramadol in treatment of chronic low back pain. J Rheumatol. 2000;27:772-778.

41. Biasi G, Manca S, Manganelli S, Marcolongo R. Tramadol in the fibromyalgia syndrome: a controlled clinical trial versus placebo. Int J Clin Pharmacol Res. 1998:18:13-19.

42. Koes BW, Scholten RJ, Mens JM, Bouter LM. Efficacy of epidural steroid injections for low-back pain and sciatica: a systematic review of randomized clinical trials. Pain. 1995:63:279-288.

43. Yelland MJ, Mar C, Pirozzo S, Schoene ML, Vercoe P. Prolotherapy injections for chronic low-back pain [review]. Cochrane Database Syst Rev. 2004(2):CD004059.

44. Kuchera WA, Kuchera ML. Osteopathic Principles in Practice. 2nd ed. Columbus, Ohio: Greyden Press; 1994.

45. Ward RC, ed. Foundations for Osteopathic Medicine. 2nd ed. Philadelphia, Pa: Lippincott Williams \& Wilkins; 2002.

46. Fishman LM, Anderson C, Rosner B. BOTOX and physical therapy in the treatment of piriformis syndrome. Am J Phys Med Rehabil. 2002;81:936-942.

47. Klein MJ. Piriformis syndrome. eMedicine Web site. Available at: http://www.emedicine.com/pmr/topic106.htm. Accessed June 14, 2004.

48. Meidan VM, Michniak BB. Emerging technologies in transdermal therapeutics. Am J Ther. 2004;11:312-316. 